\title{
REVIEW
}

\section{TRAIL signals, extracellular matrix and vessel remodelling}

\author{
Manisha S Patil1,2, Siân P Cartland1,2 and Mary M Kavurma1,2 \\ ${ }^{1}$ Heart Research Institute, Sydney, Australia \\ 2Faculty of Medicine and Health, University of Sydney, Sydney, Australia
}

Correspondence should be addressed to M M Kavurma: Mary.Kavurma@hri.org.au

\begin{abstract}
The extracellular matrix (ECM) is an essential part of the vasculature, not only providing structural support to the blood vessel wall, but also in its ability to interact with cells to regulate cell phenotype and function including proliferation, migration, differentiation and death - processes important in vascular remodelling. Increasing evidence implicates TNF-related apoptosis-inducing ligand (TRAIL) signalling in the modulation of vascular cell function and remodelling under normal and pathological conditions such as in atherosclerosis. TRAIL can also stimulate synthesis of multiple ECM components within blood vessels. This review explores the relationship between TRAIL signals, the ECM, and its implications in vessel remodelling in cardiovascular disease.
\end{abstract}

\section{Introduction}

Blood vessels, consisting of arteries, arterioles, capillaries, venules and veins, are channels with intricate networks that supply blood around the body and remove waste. Most blood vessels are composed of three layers (Fig. 1). The interior layer, called the tunica intima, consists of a monolayer of endothelial cells supported by the subendothelial space of connective tissue. This layer is always exposed to the blood and forms the first layer of defence. The tunica media is the second layer, partitioned from the intima by the internal elastic lamina, and consists predominantly of vascular smooth muscle cells (VSMCs), elastic and connective tissues, arranged in a circular fashion. The VSMCs can constrict and dilate, playing a key role in blood pressure control. The third (outer) layer of the blood vessel, the tunica adventitia, is comprised of fibroblasts and connective tissue fibres surrounded by the external elastic lamina. On the other hand, the smallest of blood vessels, the capillaries, consist of a thin endothelial cell tube, surrounded by pericytes, a mural cell, similar to VSMCs.
A major component of the blood vessel wall is the extracellular matrix (ECM). In most vessels, it is synthesised by endothelial cells, VSMCs and fibroblasts and found within the space between the tunica layers and cells, contributing to more than half of the vessel wall mass (1). In capillaries, a thin layer of ECM (or basement membrane) is located between the endothelial tubes and pericytes. ECM composition varies in each vessel type, as it is essential not only for the structural support of blood vessels, but also for the regulation of cell processes including proliferation, migration, differentiation, survival, adhesion, contractility, polarity and phenotype, as well as matrix protein synthesis, assembly and degradation (2). These processes are essential in vascular remodelling where structural changes to the blood vessel wall are necessary during normal physiology, aging, injury, and disease. Cells act in response to the ECM and remodel, but this process becomes impaired in vascular diseases such as atherosclerosis $(3,4)$. (c) 2020 The authors Published by Bioscientifica Ltd 


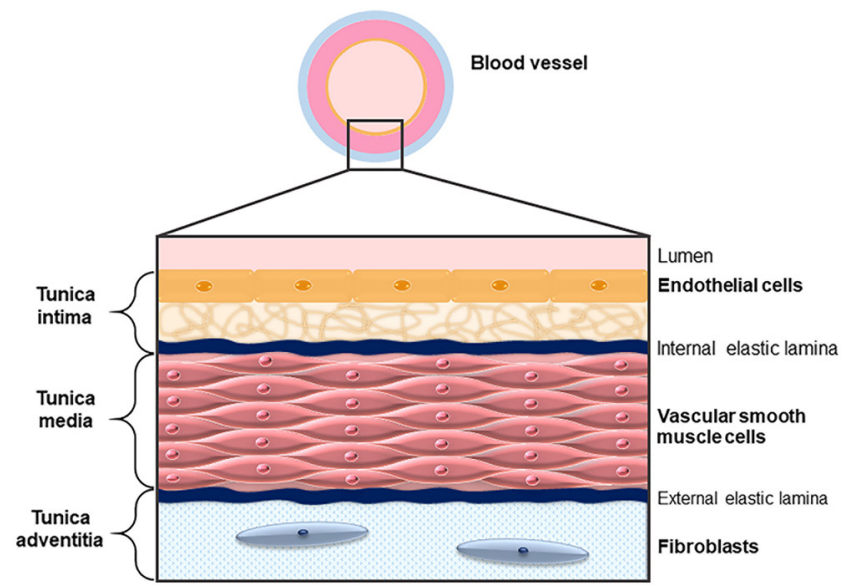

Figure 1

Structure of the blood vessel wall. The vessel wall is comprised of three layers: (1) the tunica intima, consisting of endothelial cells within the subendothelial space, (2) the tunica media, primarily composed of vascular smooth muscle cells with extracellular matrix proteins, and (3) the tunica adventitia, where fibroblasts and connective tissues reside.

TNF-related apoptosis-inducing ligand (TRAIL) was discovered for its unique ability to selectively kill cancer cells $(5,6)$. In the vasculature, TRAIL has a multifunctional role. In addition to cell death, TRAIL can contribute to cell survival, proliferation, migration and differentiation $(7,8,9)$ and in doing so modulate vascular remodelling in cardiovascular diseases (CVDs). Furthermore, in many vascular cells, TRAIL has been linked to regulating components of the ECM. This review summarises our current understanding of the contribution of TRAIL signals to the ECM and vascular remodelling in disease. A better understanding of ECM synthesis, composition, function and alterations to blood vessel remodelling in CVD could offer new strategies for treatment.

\section{ECM components, structure and function}

The ECM is a highly organised support network primed to provide cell anchorage and define tissue architecture. Each matrix protein possesses specific properties that define structural, mechanical and chemical characteristics of the ECM important for elasticity, organisation, blood vessel function and vascular cell activity (2). The major ECM proteins involved in these processes are glycosaminoglycans (GAGs), collagens, elastin, fibronectins, integrins, growth factors and matrix metalloproteases (MMPs) (Fig. 2).

GAGs are the major component of the ECM ground substance, a gel-like substance in the extracellular space, arranged as unbranched chains of repeating units of disaccharides (10). GAG chains covalently link to protein

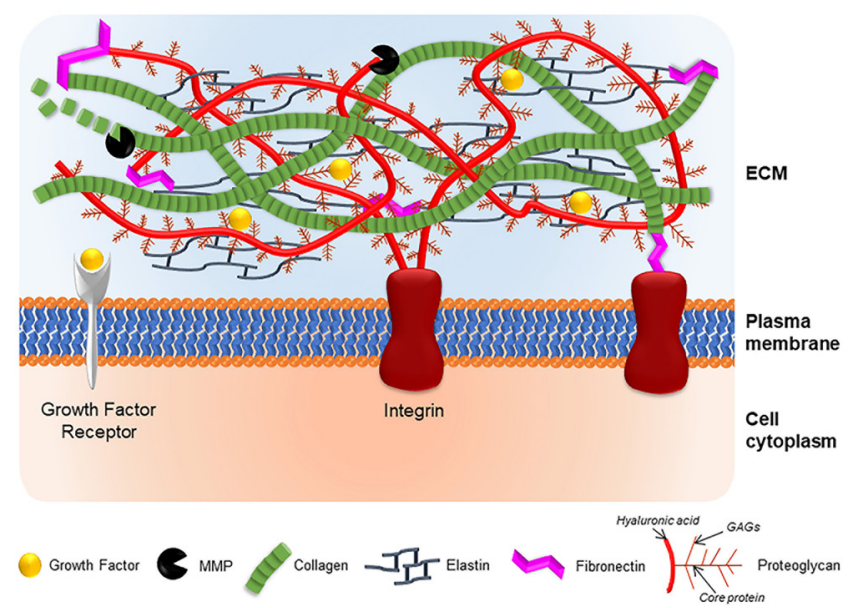

Figure 2

The ECM structure and its components. The ECM is a complex environment comprised of multiple proteins including collagens, fibronectin, proteoglycans, integrins, growth factors and metalloproteinases (MMPs). The ECM regulates a plethora of functions to maintain vessel structure and homeostasis.

core molecules to produce proteoglycans found in all layers of the vessel wall. Among many molecules, hyaluronic acid polymers form complexes with proteoglycans. Because these polymers can be large, they can displace large volumes of water, thus one function of proteoglycans is to maintain tissue hydration (11). Examples of GAGs found within the vasculature include hyaluronan and heparan sulphate; proteoglycans include syndecan, versican and aggrecan $(12,13,14)$. Proteoglycans regulate movement of molecules in and out of the matrix, as well as signal transduction (15). As such, they have a unique ability to interact with other ECM proteins including integrins, growth factors, chemokines and cytokines to modulate cellular processes (reviewed in 16).

Collagen is the most abundant matrix protein with 28 family members identified to date (17); 13 of these are found in the vascular wall, synthesised by endothelial cells, VSMCs and fibroblasts (18). They have a triple stranded helical structure arranged into fibrils which provides tensile strength (19). For example, type 1 and 3 (the most abundant collagens in the vasculature) provide strength in the media and adventitia (20), while type 7 is important for the maintenance of vessel structure (21). Collagens also interact with vascular cells to influence cellular processes and ECM regulation. For example, VSMCs interact with collagen 1, and this interaction stimulates VSMC growth and migration, as well as the production of matrix degrading enzymes, MMP2 and 9 (22). Additionally, collagen maintains the ECM by binding to other ECM proteins such as fibronectin to regulate (c) 2020 The authors Published by Bioscientifica Ltd
This work is licensed under a Creative Commons Attribution-NonCommercial-NoDerivatives 4.0 International License. ded from Bioscientifica.com at 04/25/2023 11:21:36PM 
collagen assembly, which in turn stabilises fibronectin structure during mechanical stretching (23).

Elastin is another ECM protein synthesised by vascular cells. Its precursor, tropoelastin, is secreted as a highly soluble monomer, but following post-translational modification, tropoelastin subunits are crosslinked into elastin fibres, becoming insoluble and giving elastin its durable property (24). As such, elastin is essential for the maintenance of elasticity and structure of the vessel wall. Elastin can also regulate cell behaviour. For example, elastin-derived peptides can activate the mitogenactivated protein kinase (MAPK) pathway in VSMCs to stimulate proliferation (25). Further, endothelial nitric oxide synthase (eNOS) produced by endothelial cells can be activated by tropoelastin, leading to the subsequent release of nitric oxide (NO), a molecule important for its vascular protective functions (26).

In order to interact within their microenvironment and modulate behaviour, differentiation, metabolism and survival, cells are required to interact with the ECM. They do this primarily via integrins, which are the largest family of adhesion receptors on cells, binding collagens, laminin and fibronectin in the vessel wall. By binding ECM proteins, integrins orchestrate bi-directional signals, outside-in and inside-out, to regulate endothelial cell and VSMC behaviour during vessel remodelling such as in angiogenesis (27). For example, endothelial cells interact with collagen type 1 via integrins to form new capillaries (28), and integrins on VSMCs interact with collagen in the media promoting survival and growth signals (27) as well as adhesion to the basement membrane during vessel maturation (29).

Fibronectin is a large secreted dimeric protein with multiple isoforms. In the vasculature, it is expressed on the surface of cells and becomes part of the ECM as fibronectin fibrils, a process which requires activation via binding of integrin receptors. Together with other fibres, matrix proteins and integrins, fibronectin forms a meshwork important for signalling (1). It can also be released into plasma upon induction of injury to support thrombus formation (30). The significance of fibronectin in the vessel wall was demonstrated when a fibronectin inhibitor reduced cellular proliferation, VSMC ECM secretion and differentiation, vascular remodelling, inflammatory responses and ECM accumulation following injury (31). One example of this is fibronectin's ability to regulate the production of collagen 1 fibres (32).

The ECM also consists of matrix proteases known as MMPs which are enzymes that degrade matrix proteins to release growth factors and cytokines and generate bioactive fragments capable of remodelling the vessel (2). MMP1, 2 and 9 are the most common MMPs in the vessel wall and predominantly synthesised by endothelial cells, VSMCs and fibroblasts (33). MMP production is controlled by cells via ECM-cell interactions and counterbalanced by inhibitors of MMPs, called tissue inhibitor of metalloproteinases (TIMPs), an essential mechanism required to maintain homeostasis. The ECM is also a storage reservoir for many growth factors, derived from all cells within the vasculature, including vascular endothelial growth factor (VEGF), fibroblast growth factor-2 (FGF2), platelet-derived growth factor (PDGF), insulin-like growth factor receptor-1 (IGF1R) and transforming-growth factor- $\beta 1$ (TGF $\beta 1$ ). Many of these growth factors are necessary for physiological remodelling of blood vessels, for example, in angiogenesis and blood pressure control; however, they can also act as potent mitogens and chemoattractants, contributing to abnormal cell processes (proliferation and migration) in states of pathological vascular remodelling, such as intimal thickening and atherogenesis.

\section{TRAIL signals and the ECM}

\section{TRAIL}

TRAIL is expressed on most cells as a transmembranebound protein which can be cleaved by proteases to release a soluble form. Both forms are bioactive (5). In humans, TRAIL signalling is the most complex of all TNF members because it can bind five different receptors. Although multimers have been identified $(5,34,35)$, TRAIL's most common form is a homotrimer that binds and activates its signalling receptors, death receptor- 4 and -5 (DR4 and DR5) $(36,37)$. Upon binding these, TRAIL can stimulate apoptosis by activating the caspase cascade or activating signalling pathways such as phosphoinositide 3-kinase (PI3K), MAPKs including extracellular signal-regulated kinase (ERK), Jun N-terminal kinase (JNK) and p38, as well as the transcription factor $\mathrm{NFKB}$, for pro-survival signals $(37,38,39,40,41)$. Additional receptors include decoy receptors-1, -2 (DcR1, DcR2), and osteoprotegrin (OPG), the only known secreted receptor for TRAIL, which regulates osteoclastogenesis by binding receptor activator of NFkB ligand (RANKL). It is suggested that these decoy receptors can compete with DR4 and DR5 for ligand binding and protect cells from apoptosis. However, the function(s) of TRAIL receptors in the vasculature are not fully defined. 


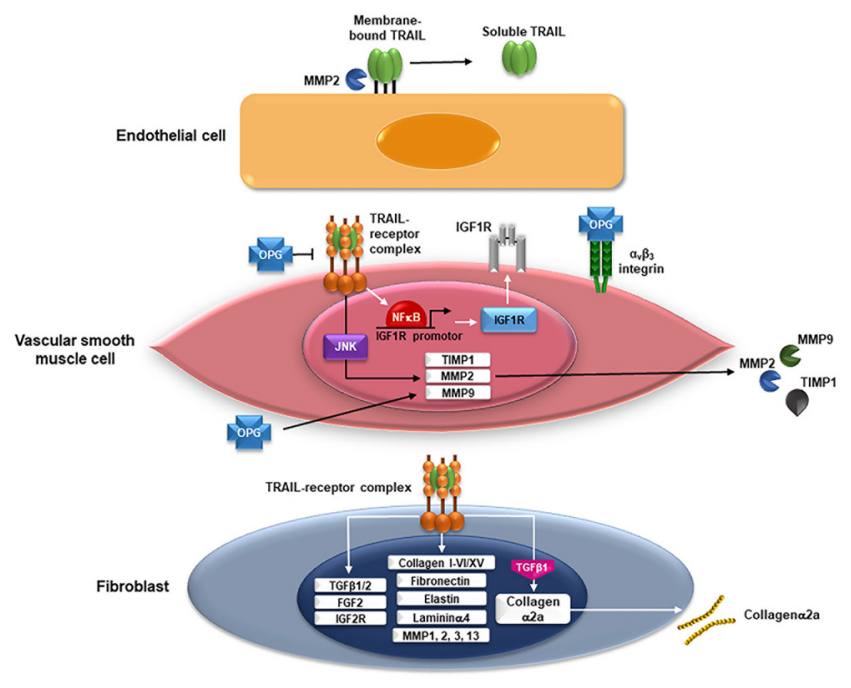

Figure 3

TRAIL signals and ECM components in vascular cells. Top, in endothelial cells, MMP2 can cleave membrane-bound TRAIL to produce a soluble form. Middle, exogenous TRAIL exposure to vascular smooth muscle cells stimulates IGF1R mRNA and protein expression via NFkB. TRAIL can stimulate MMP2, MMP9 and TIMP1 expression and secretion via JNK, whereas OPG inhibits TRAIL-induced MMP expression. In contrast, OPG exposure alone increases MMP protein expression in VSMCs. In response to hypoxia, OPG and $\alpha_{v} \beta_{3}$ integrin associate. Bottom, exogenous TRAIL exposure to fibroblasts can increase mRNA expression of ECM proteins: MMP1, 3, 11 and 13; growth factors including TGF 1 1, FGF2 and IGF2R; structural proteins including collagens 1, 6 and 15, as well as fibronectin, elastin and laminin $\alpha 4$. TRAIL-inducible expression and secretion of collagen $\alpha 2$ a occurs via TGF $\beta 1$.

\section{TRAIL and ECM components}

Although the effect of TRAIL on ECM components and function is not established, a link between TRAIL and collagen, MMP and growth factor synthesis has been described (Fig. 3). Yurovsky et al. showed that low concentrations of human recombinant TRAIL at $\sim 1 \mathrm{ng} /$ $\mathrm{mL}$ for $24 \mathrm{~h}$ significantly increased collagen $\alpha 2 \mathrm{a}$ mRNA and protein secretion from human fibroblasts, without affecting cell viability (42). Using DNA microarray hybridisation, the same group identified multiple genes important in tissue remodelling to be altered by TRAIL including collagens $1-6$, collagen 15 , fibronectin, elastin, laminin $\alpha 4$, growth factors (TGF $\beta 1 / 2$, connective tissue growth factor) and glycoproteins (thrombospondin 1/2), whereas collagen 11 and the proteoglycan decorin levels were reduced (42). To demonstrate functionality of their findings, the authors focussed on TGF $\beta 1$ signalling. They found that treatment of fibroblasts with a neutralising antibody to TGF $\beta 1$ inhibited TRAIL-mediated collagen $\alpha 2 \mathrm{a}$ gene expression and total collagen secretion, implying a TRAIL-TGF $\beta 1$-collagen axis (42). While fibroblasts express all TRAIL receptors $(43,44)$, it is unclear whether the TRAIL-TGF $\beta 1$-collagen axis involves a specific receptor. These suggest that TRAIL may contribute to the regulation of tensile strength in the blood vessel wall, in part, by regulating synthesis of collagen.

MMP2 can cleave membrane-bound TRAIL to a soluble form in endothelial cells in vitro (45); however, the extent of this occurring in other vascular cells or in vivo is unclear. It is also unclear as to whether MMPs can modulate soluble and matrix-bound TRAIL in cells or tissues to influence remodelling events. Interestingly, in fibroblasts, TRAIL can stimulate the expression of MMP13 and 13 (42), in cancer cells by increasing MMP7 and 9 $(46,47)$ and in VSMCs by increasing the expression of Mmp2, Mmp9 and Timp1 via JNK signals (48). In the latter, TRAIL-induced Mmp9 and Timp1 expression was inhibited by treatment with recombinant human OPG, suggesting that these effects may require TRAIL-OPG signalling. Indeed, treatment of RAW264.1 cells or VSMCs isolated from $A$ poe ${ }^{-/-}$mice with OPG at $4 \mathrm{nM}$ increased MMP9 protein expression, as well as MMP9 activity in Apoe-/bone marrow-derived macrophages (49). Importantly, $\mathrm{Opg}^{-/-} \mathrm{Apoe}^{-/-}$mice had increased collagen, proteoglycan and laminated elastin content in their atherosclerotic lesions (49). Interestingly, OPG can bind GAGs and proteoglycans in non-vascular cells (50); however, the extent and functional consequences of these in the vasculature is unclear. In contrast, OPGs ability to bind $\alpha_{v} \beta_{3}$ integrin in VSMCs can stimulate proliferation of these cells and contribute to disease (51). Collectively, these findings suggest that TRAIL signals may regulate ECM to control cell processes necessary for vascular remodelling.

Another ECM component that TRAIL is known to regulate is the IGF1R, a potent anti-apoptotic growth factor receptor. In VSMCs, exogenous TRAIL treatment stimulated IGF1R gene expression, whereas seruminducible IGF1R protein expression was blocked with a neutralising antibody to TRAIL (52). A novel NFkB site $(-325 /-315)$ was identified on the human IGF1R promoter responsible for TRAIL-induced IGF1R expression, since a seven-fold induction of IGF1R promoter activity was abolished when this element was mutated and NFKB binding ability inhibited (52). Interestingly, TRAIL's ability to regulate growth factor expression may be a common theme, since it can also increase IGF2R, TGF $\beta 1 / 2$ and FGF2 mRNA and/or protein expression in vascular cells $(42,53)$. Collectively, these demonstrate that TRAIL can regulate the expression of several ECM proteins and may contribute to ECM function in the blood vessel wall. Further studies are needed to delineate whether 
TRAIL signals can modulate the expression, synthesis or function of other ECM molecules such as GAGs, elastin, fibronectins and integrins.

\section{TRAIL signals and vascular remodelling}

Vascular remodelling occurs under normal physiology and during pathological disease. TRAIL-dependent processes in vascular remodelling under these conditions are summarised in Fig. 4A and B and described in greater detail subsequently.

\section{Angiogenesis}

Under normal physiology, endothelial cells contribute to vascular remodelling by releasing or activating factors to stimulate cell proliferation, migration and death, contributing to the synthesis and composition of the ECM. The endothelium plays a crucial role in maintaining barrier homeostasis, controlling exchanges between the blood and the vessel wall, controlling adherence of immune cells, modulating vessel tone, reducing VSMC proliferation and controlling thrombotic activity. Endothelial cells are also essential in angiogenesis. These processes, however, are impaired or dysregulated when the endothelium becomes dysfunctional as observed in CVD. Multiple lines of evidence indicate that TRAIL signalling can stimulate endothelial cell apoptosis, proliferation, migration, and differentiation, as well as regulate cell-cell junctions and influence cell adhesion.

Although Li et al. (2003) showed that recombinant human TRAIL used at concentrations up to $80 \mathrm{ng} / \mathrm{mL}$ killed human umbilical vein endothelial cells (HUVEC), $\sim 70 \%$ of the cultured cells survived TRAIL's cytotoxic actions, suggesting TRAIL's killing effects in these cells may require additional factors. Indeed, a marked increase in

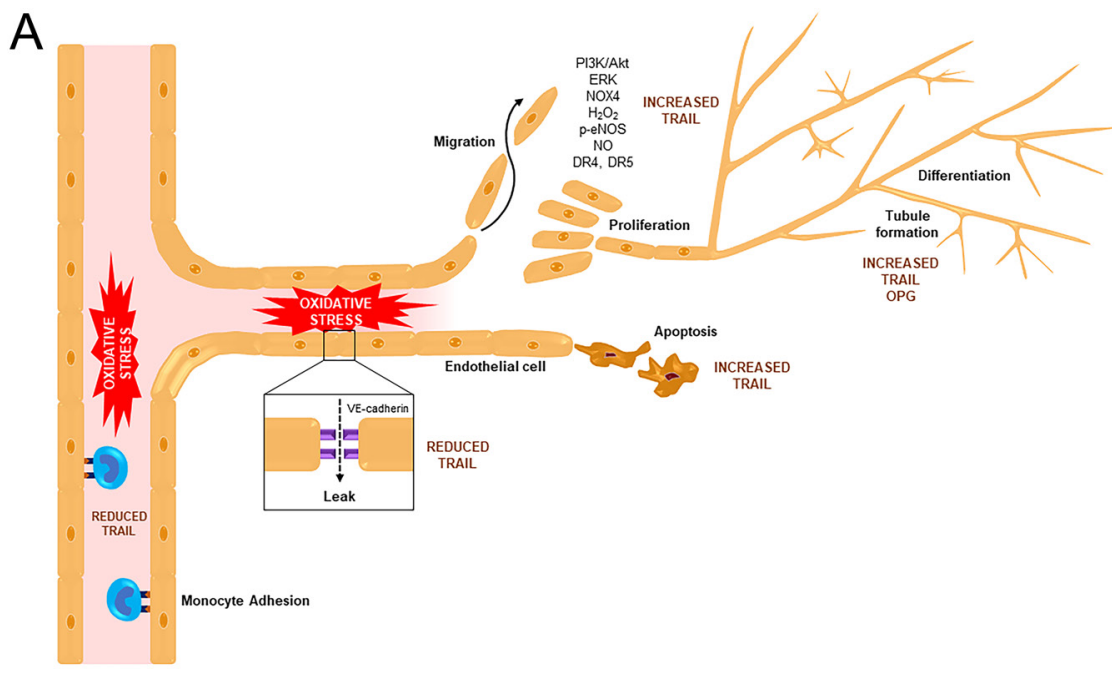

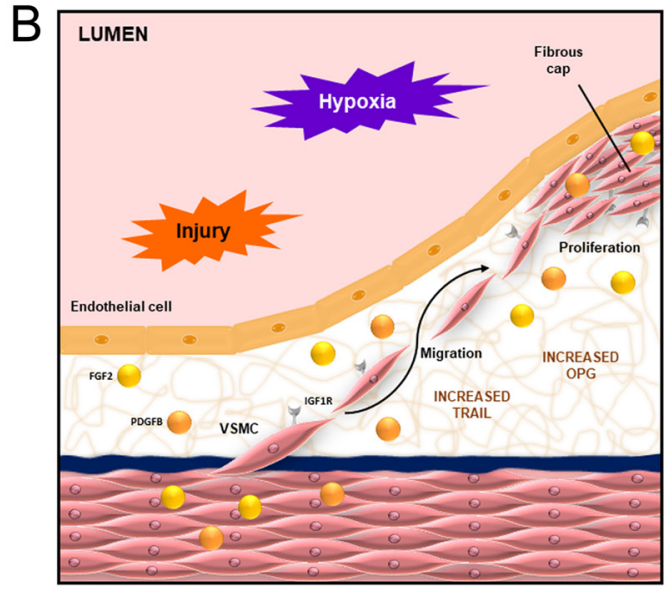

Intimal thickening

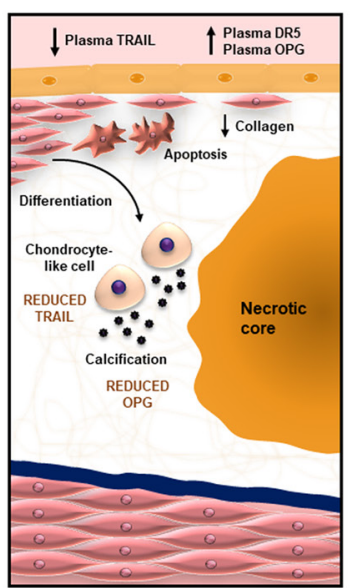

Advanced atherosclerosis

\section{Figure 4}

(A) TRAIL-dependent effects on endothelial cell processes during vascular remodelling. TRAIL stimulates endothelial cell proliferation, migration and tubule formation via activating $\mathrm{PI} 3 \mathrm{~K}, \mathrm{ERK}$ and NOX4- and $\mathrm{H}_{2} \mathrm{O}_{2}$-inducible eNOS and nitric oxide release (NO). TRAIL can stimulate expression of its receptors, DR4 and DR5. Under certain conditions of heightened stress, TRAIL promotes apoptosis of endothelial cells. TRAIL protects endothelial cells from oxidative stress, by improving vascular leak, in part, by controlling VE-cadherin reorganisation on the cell membrane and by reducing monocyte adhesion to the vessel wall. The soluble TRAIL receptor OPG can also stimulate tubule formation in endothelial cells. (B) TRAIL-dependent effects during intimal thickening and atherosclerosis. In response to injury, FGF2 or PDGFB, TRAIL stimulates VSMC migration and proliferation, contributing to atherogenesis and fibrous cap formation in atherosclerotic plaque. TRAIL also stimulates cell migration and proliferation via upregulating IGF1R. Under hypoxic conditions, TRAIL and OPG expression is augmented to modulate VSMC processes in intimal thickening. In advanced atherosclerosis, TRAIL-expressing T cells stimulate VSMC apoptosis reducing collagen content. Deletion of TRAIL accelerates atherogenesis and stimulates differentiation of VSMCs to chondrocyte-like cells. Deletion of TRAIL accelerates calcification in advanced lesions; a finding also observed with OPG deletion. A common feature in CVD is reduced circulating TRAIL levels while plasma DR5 and OPG are increased in atherosclerosis; the latter associating with disease severity. https://vb.bioscientifica.com https://doi.org/10.1530/VB-20-0005 (c) 2020 The authors Published by Bioscientifica Ltd
This work is licensed under a Creative Commons Attribution-NonCommercial-NoDerivatives 4.0 International License. ded from Bioscientifica.com at 04/25/2023 11:21:36PM 
apoptosis, up to $80 \%$, was only observed in the presence of TRAIL and the protein synthesis inhibitor cycloheximide (54). Inducible cell death was also observed in tumour endothelial cells in vitro; supported by disruption of tumour endothelium in mice treated with recombinant soluble Flag-tagged human TRAIL (55). Interestingly, this group crosslinked their soluble Flag-tagged human TRAIL with an anti-Flag antibody producing higher order oligomers, which enabled stimulation of apoptosis in multiple cancer cells (55). These suggest that, under certain circumstances, TRAIL may promote endothelial cell death in the vessel wall.

We and others have shown TRAIL to stimulate proliferation, migration and differentiation of endothelial cells into tube-like structures $(39,56,57)$ in vitro processes of angiogenesis. Human recombinant TRAIL can activate kinases important for cell survival such as Akt and ERK $(39,56)$, and although endothelial cells express DR4, DR5, DcR1 and DcR2 at similar levels (39), their role in activation of these kinases is unclear. Interestingly, $18 \mathrm{~h}$ of trophic withdrawal resulted in $\sim 45 \%$ apoptosis of HUVEC, which was rescued to $30 \%$ by TRAIL exposure, suggesting that TRAIL may act as a survival factor (39). When the system was overloaded with TNF- $\alpha$ and/or a PI3K inhibitor, TRAIL's protective effects were no longer evident, implying that, in a toxic environment (such as in advanced atherosclerosis), TRAIL's protective effects may become void. TRAIL at 10 and $100 \mathrm{ng} / \mathrm{mL}$ can also stimulate phosphorylation and trafficking of eNOS, NOS activity and generation of NO $(57,58,59)$ - key factors regulating vessel patency. Importantly, exposure of human endothelial cells to TRAIL receptor-Fc fusion proteins for DR4 and DR5 inhibited apoptosis due to serum deprivation, implicating both DR4 and DR5 in TRAIL's ability to promote survival in these cells (60).

Using a model of peripheral artery disease in mice, we identified a role for TRAIL in ischaemia-induced angiogenesis. In response to hindlimb ischaemia, Trail-/mice had impaired recovery of limb movement and increased limb necrosis, with markedly reduced $(\sim 70 \%)$ capillary density in ischaemic hindlimbs. Viral TRAIL gene therapy dramatically improved limb perfusion mediated by NOX4- and $\mathrm{H}_{2} \mathrm{O}_{2}$-inducible eNOS phosphorylation and generation of NO. These effects may be mediated by DR4 or DR5, since ischaemia and viral TRAIL gene therapy increased Dr5 mRNA expression in WT, but not in Trail ${ }^{-/}$hindlimbs, and TRAIL was shown to stimulate Dr4 mRNA expression in human endothelial cells in vitro (57). Interestingly, OPG has also been implicated in the regulation of angiogenesis (61). Using the aortic ring model, the authors showed that human recombinant OPG stimulated angiogenic sprouting, in part, by activating Akt and ERK, which was inhibited by 5 times more TRAIL (61). These findings demonstrate our lack of understanding of complex TRAIL-receptor interactions.

More recently, we showed Trail-/- mice had increased vascular leak, and in vitro, TRAIL $(10 \mathrm{ng} / \mathrm{mL})$ reduced angiotensin II-induced oxidative stress, leukocyte adhesion, and permeability by preventing redistribution of VE-cadherin from the cell membrane, an adherens junction important for endothelial cell integrity (62). Importantly, deletion of TRAIL in atherosclerotic mice resulted in endothelial dysfunction associating with increased oxidative stress and inflammation in the vessel wall (62). TRAIL regulates the production of prostanoids in HUVEC, key molecules controlling vascular tone, inflammation and leakiness, and this supports a role for TRAIL in maintaining endothelial cell function (59). However, some studies report otherwise; TRAIL (10 and $100 \mathrm{ng} / \mathrm{mL}$ ) had no effect on proliferation, migration or tubule formation using the human brain endothelial cell line, hCMEC/D3 (63). Instead, in these cells, TRAIL stimulated caspase-1 activity and cell death $(60,63)$. These discrepancies may reflect receptor expression, cell type, origin, or differences in the in vitro angiogenic assay methods used. Nevertheless, these findings suggest that TRAIL signals regulate multiple cellular functions in endothelial cells involving the ECM necessary for vascular remodelling.

\section{Intimal thickening}

Under normal conditions, VSMCs are quiescent and contractile in phenotype, exhibiting minimal proliferation and migration. However, VSMCs are remarkably plastic in nature, and in response to environmental and mechanical cues, they can change and become 'synthetic', adopting a proliferative form, capable of synthesising ECM (64). Proliferation of VSMCs can contribute to the remodelling of the vessel wall early in lesion development, leading to intimal thickening. We and others have shown that low physiological levels of TRAIL stimulate VSMC proliferation, migration and survival $(52,65,66,67$, 68). Although all receptors are expressed in human VSMCs, albeit at different levels, we showed that TRAILinduced human VSMC proliferation was inhibited with neutralising antibodies to DR4 and DcR1, but not to neutralising antibodies targeting DcR1, OPG or using Fc-DR5 (52). These suggest that TRAIL's proliferative effects

This work is licensed under a Creative Commons Attribution-NonCommercial-NoDerivatives 4.0 International License. ded from Bioscientifica.com at 04/25/2023 11:21:36PM 
are mediated by signalling and decoy TRAIL receptors. Interestingly, TRAIL-inducible aortic VSMC migration was blocked by recombinant OPG (48); OPG acting as a true decoy receptor in this setting.

Because growth factors reside in the ECM and modulate cell processes by actively interacting and signalling with other ECM components, there is some evidence linking TRAIL to growth factor signalling to regulate cell proliferation and migration in disease. For example, in people, TRAIL expression was evident in the intima of failed saphenous vein bypass grafts, co-localising with proliferating VSMCs and the IGF1R, but not active caspase-3 (52); pharmacologically blocking IGF1R's actions can inhibit VSMC proliferation in vitro and in vivo (69). Importantly, TRAIL-induced VSMC proliferation was inhibited with IGF1R antisense oligonucleotides, but not with control oligonucleotides, confirming that TRAIL-induced VSMC proliferation, in part, involved the IGF1R (52) and that this process may contribute to vessel remodelling during intimal thickening and atherogenesis.

PDGFB, is a mitogen and potent chemoattractant involved in the promotion of atherogenesis; inhibition of PDGFB or its receptor PDGFR $\beta$ reduced intimal thickening and VSMC proliferation following carotid injury compared to control rat (70), whereas increased PDGFR $\beta$ signalling augmented atherosclerosis in $A p o e^{-/-}$and $L d l r^{-/-}$mice (71). In addition to the TRAIL-IGF1R axis described previously, PDGFB can regulate TRAIL gene expression and stimulate VSMC proliferation and migration. We showed evidence of PDGFB in modulating chromatin and implicated Sp1acetylated histone-3-p300 interactions to stimulate TRAIL transcriptional activity and gene expression. Importantly, PDGFB-induced VSMC proliferation and migration was inhibited using siRNA targeting TRAIL, and in support, Trail $^{-/}$VSMCs displayed impaired PDGFB inducible responses to cell proliferation and migration, revealing a novel role for TRAIL in PDGFB-stimulated processes that modulate vessel remodelling (67).

FGF2 is a potent growth factor, released from VSMCs within minutes in response to injury to the vessel wall (53). Intimal thickening is an early stage of atherosclerosis development and can be induced experimentally using multiple methods including placement of a non-occlusive cuff around the femoral artery. We showed that Trail-/mice were protected from intimal thickening, whereas WT mice developed neointimal hyperplasia 15 days after cuff placement (53). VSMC proliferation and neointimal thickening was dependent on injury- and FGF2-inducible Trail expression, mediated by the transcription factor complex containing $\mathrm{Sp} 1$ and $\mathrm{NF \kappa B}$ (53). Interestingly, FGF2 expression was down-regulated in injured femoral arteries of Trail $^{-/-}$mice with reduced neointimal thickening. Collectively, these findings suggest an interplay between FGF2 and TRAIL in the ECM necessary for remodelling following injury to the vessel wall.

\section{Pulmonary hypertension}

Like intimal thickening, pulmonary hypertension (PAH) is caused by aberrant proliferation and migration of VSMCs resulting in medial thickening of pulmonary vessels, namely the arterioles. Clinically, PAH is characterised by an elevation in pulmonary artery pressure and right ventricular hypertrophy, leading to right ventricular failure. In 2012, Hameed et al. identified TRAIL as an important mediator of this disease (68). The authors showed that TRAIL expression was increased in vascular cells isolated from PAH patients and in the pulmonary vasculature of multiple models of experimental PAH, implying that increased TRAIL expression in pulmonary vessels may cause PAH features. Indeed, anti-TRAIL antibody treatment returned the elevated right ventricular systolic pressure, elevated right ventricular end-diastolic pressure, and reduced pulmonary artery acceleration time, back to normal compared to IgG-treated rats. Notably, the anti-TRAIL antibody prevented pathological remodelling of VSMCs observed in the pulmonary vasculature; findings which were confirmed genetically since Trail $^{-/}$mice were protected from chronic hypoxia-induced PAH (68). Similarly, in a more severe murine PAH model, sugenhypoxia, Trail-/- mice displayed no echocardiographic or haemodynamic signs with reduced proliferative pulmonary vascular remodelling in the media compared to WT mice (72).

OPG has also been implicated to play a role in PAH since soluble levels are increased in serum of patients compared to control and its expression is elevated in human PAH lung samples, correlating with severity of disease $(51,73)$. Furthermore, OPG expression was increased in VSMCs in vivo, in hypoxia- and sugen-induced $\mathrm{PAH}$ (51). Consistent with these, $\mathrm{PAH}$ was attenuated in $\mathrm{Opg}^{-/-}$mice, whereas OPG reconstitution exacerbated disease, suggesting that OPG may regulate processes that promote PAH pathology. Indeed, OPG stimulated VSMC proliferation and migration, and these processes were mediated via $\alpha_{v} \beta_{3}$ integrin, since immunoprecipitation studies revealed the physical association of OPG with integrin $\alpha_{\mathrm{v}} \beta_{3}$, but not with $\alpha_{1}$ and $\alpha_{8}$ in hypoxia (51). Furthermore, the authors

This work is licensed under a Creative Commons Attribution-NonCommercial-NoDerivatives 4.0 International License. ded from Bioscientifica.com at 04/25/2023 11:21:36PM 
identified that OPG-mediated proliferation of VSMCs occurred via activation of $\alpha_{v} \beta_{3}$ integrin/FAK/Akt signals, since blocking $\alpha_{v} \beta_{3}$ integrin using siRNA technology in the presence of OPG prevented phosphorylation of FAK and Akt, and VSMC proliferation (51). More recently, OPG's pro-proliferative and pro-migratory effects in VSMCs was found to be mediated via another TNF receptor, Fas (74). Here, the authors established that the physical interaction of OPG with Fas was necessary to activate cell proliferation, migration and survival of pig aortic VSMCs, since neutralising Fas inhibited these processes (74). Most significantly, the therapeutic potential of OPG in attenuating established PAH was shown - treatment of mice with a human antibody targeting OPG in multiple models of PAH inhibited pulmonary vascular remodelling and features of PAH (74). Collectively, these findings confirm a role for TRAIL and TRAIL receptors in remodelling of the vasculature during disease.

\section{Atherosclerosis}

VSMCs are critical for maintaining the physiological functioning of the vasculature. Not only can they contract and relax, contributing to blood pressure control, but like fibroblasts, they are a major source of collagen synthesis. Studies by our group showed that Trail $^{-/}$Apoe $e^{-/-}$mice had accelerated atherosclerosis, displaying vulnerable plaque with large necrotic cores, thin fibrous caps, and significantly increased macrophage accumulation and apoptosis observed in the cap and shoulder regions of the plaque compared to Apoe-/- mice (75). Importantly, lesions of mice lacking TRAIL had significantly reduced VSMC and collagen content, suggesting that in advanced lesions the presence of TRAIL may be necessary for VSMC survival, collagen synthesis, stability, and tensile strength of the vessel wall. Indeed, recombinant TRAIL administration to diabetic Apoe-/- mice increased VSMCpositive cell numbers within the plaque cap with a tendency for increased collagen (76). These are significant since plasma TRAIL levels are suppressed in patients with atherosclerosis $(77,78,79,80)$.

TRAIL receptors have also been implicated in atherosclerotic disease. For example, plasma OPG and DR5 levels are increased in stroke patients with large artery atherosclerosis (80) and a significant positive correlation was identified between plasma OPG and severity of coronary artery disease (81). OPG and DR5 are also expressed in human atherosclerotic tissues $(82,83)$ and predominantly by VSMCs $(83,84)$. However, in contrast to increased plasma levels and expression in human disease, $\mathrm{Opg}^{-/-} \mathrm{Apoe^{-/- }}$ mice had accelerated atherosclerosis compared to Apoe-/- mice at 40 and 60 weeks of age, and unlike Trail-/-Apoe ${ }^{-/-}$lesions, atherosclerotic lesions from $\mathrm{Opg}^{-/-} \mathrm{Apoe}^{-/-}$had significantly more collagen deposition, although VSMC content was not measured (49). The role of DR5 in atherosclerotic disease is yet to be established, but adoptively transferred TRAILexpressing CD4 $\mathrm{T}$ cells induced VSMC apoptosis via DR5 in atherosclerotic plaque engrafted into immunodeficient mice (83). How TRAIL-dependent VSMC apoptosis effected plaque stability, collagen content or other ECM components was not examined.

\section{Calcification}

Within the ECM, multiple ECM proteins (e.g. collagens and proteoglycans) provide charged regions where calcium phosphate can accumulate (85). Abnormal deposition of calcium phosphate salts or hydroxyapatite in the vascular wall (vascular calcification) not only contributes to vascular stiffness but is a major risk factor for the morbidity and mortality associated with CVDs including atherosclerosis (85). As mentioned earlier, VSMCs are incredibly plastic, and in addition to the synthetic phenotype, they are able maintain a spectrum of phenotypes in the vasculature including becoming adipocytes, foam cells, or osteochondrogenic (bone-forming) cells (86). Previous work by our group showed that atherosclerotic lesions from Apoe-/- mice lacking TRAIL had significantly more chondrocyte-like cells, which secrete cartilage matrix, as well as increased calcification in plaque compared to atherosclerotic lesions from $A p o e^{-/-}$mice alone (87). An alizarin red assay was performed to assess calcification in vitro; VSMCs isolated from Trail-/- $^{-}$or $\mathrm{Trail}^{+/+}$mice were grown in osteogenic media, and Trail-/- VSMCs developed more calcification compared to $\mathrm{Trail}^{+/+}$VSMCs, suggesting that TRAIL inhibits VSMC osteochondrogenic transdifferentiation (87). Indeed, exogenous recombinant TRAIL attenuated calcium-induced calcification of human VSMCs, in part, by inhibiting RANKL (87), an initiator of osteoclastogenesis. In support of these findings, Zauli et al. demonstrated that recombinant TRAIL inhibits osteoclastogenesis (88); however, others report the opposite; recombinant TRAIL promoted calcification of human VSMCs (89), and TRAIL was detected in tissues from patients with calcific aortic valvular disease associating with cell death (90). This group did not examine the effect of TRAIL on VSMCs in vitro, but they found that exogenous TRAIL treatment of valvular interstitial cells isolated from patients with calcific disease had enhanced calcification

This work is licensed under a Creative Commons Attribution-NonCommercial-NoDerivatives 4.0 International License. aded from Bioscientifica.com at 04/25/2023 11:21:36PM 
in osteochondrogenic media vs non-calcific cells (90). Furthermore, calcific interstitial cells expressed more DR4, DR5, DcR1 and DcR2 compared to non-calcific cells, whereas only DR4 expression was enhanced in response to osteogenic media (90), suggesting that TRAIL's effects dependent on DR4 may be cell-type specific and reliant on the local micro-environment.

Like DR4, DR5, DcR1, and DcR2 expression in calcified interstitial cells described previously, OPG is also expressed in arteries of aged $\mathrm{Apoe}^{-/-}$mice with significantly more chondrocyte-like cells (91), suggesting that OPG expression may associate with calcification. However, OPG deletion in $\mathrm{Apoe}^{-/-}$mice accelerated calcification in the vessel wall. In this study, calcium content was measured by Von Kossa staining from brachiocephalic arteries of $\mathrm{Opg}^{-/-} \mathrm{Apoe}^{-/-}$mice and compared to littermate control arteries, showing increased calcification within the media and intima which was age dependent (49). Aortic calcium content was also increased $\sim 12$-fold in 60-week-old $\mathrm{Opg}^{-/-} \mathrm{Apoe}^{-/-}$vs $\mathrm{Opg}^{+/+} \mathrm{Apoe}^{-/-}$mice, and interestingly, mice lacking OPG had elevated levels of plasma RANKL, $\sim 4$-fold, suggesting that mechanisms controlling bone turnover may also be relevant in vascular calcification (49). These studies show that TRAIL signals play important role(s) in the blood vessel wall; however, further work is warranted to understand the TRAIL-receptor contribution.

\section{Conclusions and future perspectives}

The remodelling of the vasculature is a key response in physiology and in pathology. Although there have been significant advances in our understanding of remodelling events in the blood vessel wall, these processes are highly complex, involving multiple cells, the expression of genes, their secreted factors, the ECM and the local microenvironment. TRAIL was identified because of its ability to selectively kill cancer cells and leave normal cells resistant to its cytotoxic actions. The emerging concept that TRAIL through its multiple receptors also regulates vascular cell survival, proliferation, migration, differentiation, permeability, adhesion, ECM expression and synthesis suggests that it plays a key role in the profound changes to the architecture of the blood vessel wall during vascular remodelling. Understanding how TRAIL signals control these responses and interact with the ECM under normal and in disease states would increase knowledge that could offer new and selective therapeutic strategies for adjusting undesirable processes during vascular remodelling.

\section{Declaration of interest}

The authors declare that there is no conflict of interest that could be perceived as prejudicing the impartiality of this review.

\section{Funding}

This work was supported by the National Health and Medical Research Council of Australia Ideas Grant (\#G203414).

Author contributions statement

$\mathrm{M} \mathrm{P}, \mathrm{SC}$ and $\mathrm{M} \mathrm{K}$ contributed to writing this review.

\section{References}

$1 \mathrm{Xu} \mathrm{J} \&$ Shi GP. Vascular wall extracellular matrix proteins and vascular diseases. Biochimica et Biophysica Acta 20141842 2106-2119. (https://doi.org/10.1016/j.bbadis.2014.07.008)

2 Yue B. Biology of the extracellular matrix: an overview. Journal of Glaucoma 201423 (Supplement 1) S20-S23. (https://doi.org/10.1097/ IJG.0000000000000108)

3 Bae H, Puranik AS, Gauvin R, Edalat F, Carrillo-Conde B, Peppas NA, Khademhosseini A \& Khademhosseini A. Building vascular networks. Science Translational Medicine 20124 160ps23. (https://doi. org/10.1126/scitranslmed.3003688)

4 Ponticos M \& Smith BD. Extracellular matrix synthesis in vascular disease: hypertension, and atherosclerosis. Journal of Biomedical Research 201428 25-39. (https://doi.org/10.7555/JBR.27.20130064)

5 Wiley SR, Schooley K, Smolak PJ, Din WS, Huang CP, Nicholl JK, Sutherland GR, Smith TD, Rauch C \& Smith CA. Identification and characterization of a new member of the TNF family that induces apoptosis. Immunity 19953 673-682. (https://doi.org/10.1016/10747613(95)90057-8)

6 Pitti RM, Marsters SA, Ruppert S, Donahue CJ, Moore A \& Ashkenazi A. Induction of apoptosis by Apo-2 ligand, a new member of the tumor necrosis factor cytokine family. Journal of Biological Chemistry 1996271 12687-12690. (https://doi.org/10.1074/jbc.271.22.12687)

7 Di Pietro R \& Zauli G. Emerging non-apoptotic functions of tumor necrosis factor-related apoptosis-inducing ligand (TRAIL)/Apo2L. Journal of Cellular Physiology 2004201 331-340. (https://doi. org/10.1002/jcp.20099)

8 Kavurma MM, Tan NY \& Bennett MR. Death receptors and their ligands in atherosclerosis. Arteriosclerosis, Thrombosis, and Vascular Biology 200828 1694-1702. (https://doi.org/10.1161/ ATVBAHA.107.155143)

9 Azahri NS \& Kavurma MM. Transcriptional regulation of tumour necrosis factor-related apoptosis-inducing ligand. Cellular and Molecular Life Sciences 201370 3617-3629. (https://doi.org/10.1007/ s00018-013-1264-x)

10 Rhodes JM \& Simons M. The extracellular matrix and blood vessel formation: not just a scaffold. Journal of Cellular and Molecular Medicine 200711 176-205. (https://doi.org/10.1111/j.1582-4934.2007.00031.x)

11 Yanagishita M. Function of proteoglycans in the extracellular matrix. Acta Pathologica Japonica 199343 283-293. (https://doi. org/10.1111/j.1440-1827.1993.tb02569.x)

12 Fukai N, Kenagy RD, Chen L, Gao L, Daum G \& Clowes AW. Syndecan-1: an inhibitor of arterial smooth muscle cell growth and intimal hyperplasia. Arteriosclerosis, Thrombosis, and Vascular Biology 200929 1356-1362. (https://doi.org/10.1161/ATVBAHA.109.190132)

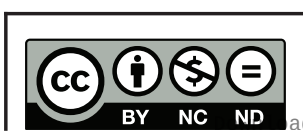

This work is licensed under a Creative Commons Attribution-NonCommercial-NoDerivatives 4.0 International License. ded from Bioscientifica.com at 04/25/2023 11:21:36PM 
13 Kenagy RD, Plaas AH \& Wight TN. Versican degradation and vascular disease. Trends in Cardiovascular Medicine 200616 209-215. (https:// doi.org/10.1016/j.tcm.2006.03.011)

14 Suna G, Wojakowski W, Lynch M, Barallobre-Barreiro J, Yin X, Mayr U, Baig F, Lu R, Fava M, Hayward R, et al. Extracellular matrix proteomics reveals interplay of aggrecan and aggrecanases in vascular remodeling of stented coronary arteries. Circulation $2018 \mathbf{1 3 7}$ 166-183. (https://doi.org/10.1161/CIRCULATIONAHA.116.023381)

15 Iozzo RV \& Schaefer L. Proteoglycan form and function: a comprehensive nomenclature of proteoglycans. Matrix Biology 2015 42 11-55. (https://doi.org/10.1016/j.matbio.2015.02.003)

16 Theocharis AD, Skandalis SS, Gialeli C \& Karamanos NK. Extracellular matrix structure. Advanced Drug Delivery Reviews 2016 97 4-27. (https://doi.org/10.1016/j.addr.2015.11.001)

17 Ricard-Blum S. The collagen family. Cold Spring Harbor Perspectives in Biology 20113 a004978. (https://doi.org/10.1101/cshperspect. a004978)

18 Plenz GA, Deng MC, Robenek H \& Völker W. Vascular collagens: spotlight on the role of type VIII collagen in atherogenesis. Atherosclerosis 2003166 1-11. (https://doi.org/10.1016/s00219150(01)00766-3)

19 Kular JK, Basu S \& Sharma RI. The extracellular matrix: structure, composition, age-related differences, tools for analysis and applications for tissue engineering. Journal of Tissue Engineering 2014 5 2041731414557112. (https://doi.org/10.1177/2041731414557112)

20 Wagenseil JE \& Mecham RP. Vascular extracellular matrix and arterial mechanics. Physiological Reviews 200989 957-989. (https://doi. org/10.1152/physrev.00041.2008)

21 Sakai LY, Keene DR, Morris NP \& Burgeson RE. Type VII collagen is a major structural component of anchoring fibrils. Journal of Cell Biology 1986103 1577-1586. (https://doi.org/10.1083/jcb.103.4.1577)

22 Hou G, Vogel WF \& Bendeck MP. Tyrosine kinase activity of discoidin domain receptor 1 is necessary for smooth muscle cell migration and matrix metalloproteinase expression. Circulation Research 200290 1147-1149. (https://doi.org/10.1161/01.res.0000022166.74073.f8)

23 Kubow KE, Vukmirovic R, Zhe L, Klotzsch E, Smith ML, Gourdon D, Luna S \& Vogel V. Mechanical forces regulate the interactions of fibronectin and collagen I in extracellular matrix. Nature Communications 20156 8026. (https://doi.org/10.1038/ncomms9026)

24 Baldock C, Oberhauser AF, Ma L, Lammie D, Siegler V, Mithieux SM, Tu Y, Chow JY, Suleman F, Malfois M, et al. Shape of tropoelastin, the highly extensible protein that controls human tissue elasticity. PNAS 2011108 4322-4327. (https://doi.org/10.1073/pnas.1014280108)

25 Mochizuki S, Brassart B \& Hinek A. Signaling pathways transduced through the elastin receptor facilitate proliferation of arterial smooth muscle cells. Journal of Biological Chemistry $200227744854-44863$. (https://doi.org/10.1074/jbc.M205630200)

26 Hiob MA, Trane AE, Wise SG, Bernatchez PN \& Weiss AS. Tropoelastin enhances nitric oxide production by endothelial cells Nanomedicine 201611 1591-1597. (https://doi.org/10.2217/nnm2016-0052)

27 Niland S \& Eble JA. Integrin-mediated cell-matrix interaction in physiological and pathological blood vessel formation. Journal of Oncology 20122012 125278. (https://doi.org/10.1155/2012/125278)

28 Sweeney SM, DiLullo G, Slater SJ, Martinez J, Iozzo RV, LauerFields JL, Fields GB \& San Antonio JD. Angiogenesis in collagen I requires alpha2beta1 ligation of a GFP*GER sequence and possibly p38 MAPK activation and focal adhesion disassembly. Journal of Biological Chemistry 2003278 30516-30524. (https://doi. org/10.1074/jbc.M304237200)

29 Scheppke L, Murphy EA, Zarpellon A, Hofmann JJ, Merkulova A, Shields DJ, Weis SM, Byzova TV, Ruggeri ZM, Iruela-Arispe ML, et al. Notch promotes vascular maturation by inducing integrinmediated smooth muscle cell adhesion to the endothelial basement membrane. Blood 2012119 2149-2158. (https://doi.org/10.1182/ blood-2011-04-348706)
30 To WS \& Midwood KS. Plasma and cellular fibronectin: distinct and independent functions during tissue repair. Fibrogenesis and Tissue Repair 2011421 . (https://doi.org/10.1186/1755-1536-4-21)

31 Chiang HY, Korshunov VA, Serour A, Shi F \& Sottile J. Fibronectin is an important regulator of flow-induced vascular remodeling. Arteriosclerosis, Thrombosis, and Vascular Biology 200929 1074-1079. (https://doi.org/10.1161/ATVBAHA.108.181081)

32 Shi F, Harman J, Fujiwara K \& Sottile J. Collagen I matrix turnover is regulated by fibronectin polymerization. American Journal of Physiology: Cell Physiology 2010298 C1265-C1275. (https://doi. org/10.1152/ajpcell.00341.2009)

33 Wang X \& Khalil RA. Matrix metalloproteinases, vascular remodeling, and vascular disease. Advances in Pharmacology 201881 241-330. (https://doi.org/10.1016/bs.apha.2017.08.002)

34 Chinnaiyan AM, Prasad U, Shankar S, Hamstra DA, Shanaiah M, Chenevert TL, Ross BD \& Rehemtulla A. Combined effect of tumor necrosis factor-related apoptosis-inducing ligand and ionizing radiation in breast cancer therapy. PNAS 200097 1754-1759. (https://doi.org/10.1073/pnas.030545097)

35 Trabzuni D, Famulski KS \& Ahmad M. Functional analysis of tumour necrosis factor-alpha-related apoptosis-inducing ligand (TRAIL): cysteine-230 plays a critical role in the homotrimerization and biological activity of this novel tumoricidal cytokine. Biochemical Journal 2000350 505-510. (https://doi.org/10.1042/bj3500505)

36 Pan G, O'Rourke K, Chinnaiyan AM, Gentz R, Ebner R, Ni J \& Dixit VM. The receptor for the cytotoxic ligand TRAIL. Science 1997 276 111-113. (https://doi.org/10.1126/science.276.5309.111)

37 Schneider P, Thome M, Burns K, Bodmer JL, Hofmann K, Kataoka T, Holler N \& Tschopp J. TRAIL receptors 1 (DR4) and 2 (DR5) signal FADD-dependent apoptosis and activate NF-kappaB. Immunity 1997 7 831-836. (https://doi.org/10.1016/s1074-7613(00)80401-x)

38 Tran SE, Holmstrom TH, Ahonen M, Kahari VM \& Eriksson JE. MAPK/ERK overrides the apoptotic signaling from Fas, TNF, and TRAIL receptors. Journal of Biological Chemistry 2001276 16484-16490. (https://doi.org/10.1074/jbc.M010384200)

39 Secchiero P, Gonelli A, Carnevale E, Milani D, Pandolfi A, Zella D $\&$ Zauli G. TRAIL promotes the survival and proliferation of primary human vascular endothelial cells by activating the Akt and ERK pathways. Circulation 2003107 2250-2256. (https://doi. org/10.1161/01.CIR.0000062702.60708.C4)

40 Chaudhary PM, Eby M, Jasmin A, Bookwalter A, Murray J \& Hood L. Death receptor 5, a new member of the TNFR family, and DR4 induce FADD-dependent apoptosis and activate the NF-kappaB pathway. Immunity 19977 821-830. (https://doi.org/10.1016/s10747613(00)80400-8)

41 Muhlenbeck F, Haas E, Schwenzer R, Schubert G, Grell M, Smith C, Scheurich P \& Wajant H. TRAIL/Apo2L activates c-Jun NH2-terminal kinase (JNK) via caspase-dependent and caspase-independent pathways. Journal of Biological Chemistry 1998273 33091-33098. (https://doi.org/10.1074/jbc.273.49.33091)

42 Yurovsky VV. Tumor necrosis factor-related apoptosis-inducing ligand enhances collagen production by human lung fibroblasts American Journal of Respiratory Cell and Molecular Biology 200328 225-231. (https://doi.org/10.1165/rcmb.2002-01400C)

43 Crowder RN, Dicker DT \& El-Deiry WS. The deubiquitinase inhibitor PR-619 sensitizes normal human fibroblasts to tumor necrosis factor-related apoptosis-inducing ligand (TRAIL)-mediated cell death. Journal of Biological Chemistry 2016291 5960-5970. (https://doi. org/10.1074/jbc.M115.713545)

44 Tunyogi-Csapo M, Kis-Toth K, Radacs M, Farkas B, Jacobs JJ, Finnegan A, Mikecz K \& Glant TT. Cytokine-controlled RANKL and osteoprotegerin expression by human and mouse synovial fibroblasts: fibroblast-mediated pathologic bone resorption. Arthritis and Rheumatism 200858 2397-2408. (https://doi.org/10.1002/art.23653)

45 Secchiero P, Gonelli A, Corallini F, Ceconi C, Ferrari R \& Zauli G. Metalloproteinase 2 cleaves in vitro recombinant TRAIL: potential

This work is licensed under a Creative Commons Attribution-NonCommercial-NoDerivatives 4.0 International License. ded from Bioscientifica.com at 04/25/2023 11:21:36PM 
implications for the decreased serum levels of TRAIL after acute myocardial infarction. Atherosclerosis 2010211 333-336. (https://doi. org/10.1016/j.atherosclerosis.2010.02.024)

46 Fingas CD, Blechacz BR, Smoot RL, Guicciardi ME, Mott J, Bronk SF, Werneburg NW, Sirica AE \& Gores GJ. A smac mimetic reduces TNF related apoptosis inducing ligand (TRAIL)-induced invasion and metastasis of cholangiocarcinoma cells. Hepatology 201052 550-561. (https://doi.org/10.1002/hep.23729)

47 Kim JH, Choi C, Benveniste EN \& Kwon D. TRAIL induces MMP-9 expression via ERK activation in human astrocytoma cells. Biochemical and Biophysical Research Communications 2008377 195-199. (https://doi.org/10.1016/j.bbrc.2008.09.095)

48 Bumdelger B, Kokubo H, Kamata R, Fujii M, Yoshimura K, Aoki H, Orita Y, Ishida T, Ohtaki M, Nagao M, et al. Osteoprotegerin prevents development of abdominal aortic aneurysms. PLOS ONE 201611 e0147088. (https://doi.org/10.1371/journal.pone.0147088)

49 Bennett BJ, Scatena M, Kirk EA, Rattazzi M, Varon RM, Averill M, Schwartz SM, Giachelli CM \& Rosenfeld ME. Osteoprotegerin inactivation accelerates advanced atherosclerotic lesion progression and calcification in older ApoE-/- mice. Arteriosclerosis, Thrombosis, and Vascular Biology 200626 2117-2124. (https://doi.org/10.1161/01. ATV.0000236428.91125.e6)

50 Baud'huin M, Duplomb L, Teletchea S, Lamoureux F, RuizVelasco C, Maillasson M, Redini F, Heymann MF \& Heymann D. Osteoprotegerin: multiple partners for multiple functions. Cytokine and Growth Factor Reviews 201324 401-409. (https://doi. org/10.1016/j.cytogfr.2013.06.001)

51 Jia D, Zhu Q, Liu H, Zuo C, He Y, Chen G \& Lu A. Osteoprotegerin disruption attenuates HySu-induced pulmonary hypertension through integrin alphavbeta3/FAK/AKT pathway suppression. Circulation: Cardiovascular Genetics 201710 e001591. (https://doi. org/10.1161/CIRCGENETICS.116.001591)

52 Kavurma MM, Schoppet M, Bobryshev YV, Khachigian LM \& Bennett MR. TRAIL stimulates proliferation of vascular smooth muscle cells via activation of NF-kappa B and induction of insulinlike growth factor-1 receptor. Journal of Biological Chemistry 2008283 7754-7762. (https://doi.org/10.1074/jbc.M706927200)

53 Chan J, Prado-Lourenco L, Khachigian LM, Bennett MR, Di Bartolo BA \& Kavurma MM. TRAIL promotes VSMC proliferation and neointima formation in a FGF-2-, Sp1 phosphorylation-, and NFkappaB-dependent manner. Circulation Research 2010106 1061-1071. (https://doi.org/10.1161/CIRCRESAHA.109.206029)

$54 \mathrm{Li} \mathrm{JH}$, Kirkiles-Smith NC, McNiff JM \& Pober JS. TRAIL induces apoptosis and inflammatory gene expression in human endothelial cells. Journal of Immunology 2003171 1526-1533. (https://doi. org/10.4049/jimmunol.171.3.1526)

55 Wilson NS, Yang A, Yang B, Couto S, Stern H, Gogineni A, Pitti R, Marsters S, Weimer RM, Singh M, et al. Proapoptotic activation of death receptor 5 on tumor endothelial cells disrupts the vasculature and reduces tumor growth. Cancer Cell 201222 80-90. (https://doi. org/10.1016/j.ccr.2012.05.014)

56 Cartland SP, Genner SW, Zahoor A \& Kavurma MM. Comparative evaluation of TRAIL, FGF-2 and VEGF-A-induced angiogenesis in vitro and in vivo. International Journal of Molecular Sciences 2016172025. (https://doi.org/10.3390/ijms17122025)

57 Di Bartolo BA, Cartland SP, Prado-Lourenco L, Griffith TS, Gentile C, Ravindran J, Azahri NS, Thai T, Yeung AW, Thomas SR, et al. Tumor necrosis factor-related apoptosis-inducing ligand (TRAIL) promotes angiogenesis and ischemia-induced neovascularization via NADPH oxidase 4 (NOX4) and nitric oxide-dependent mechanisms. Journal of the American Heart Association 20154 e002527. (https://doi. org/10.1161/JAHA.115.002527)

58 Di Pietro R, Mariggiò MA, Guarnieri S, Sancilio S, Giardinelli A, Di Silvestre S, Consoli A, Zauli G \& Pandolfi A. Tumor necrosis factorrelated apoptosis-inducing ligand (TRAIL) regulates endothelial nitric oxide synthase (eNOS) activity and its localization within the human vein endothelial cells (HUVEC) in culture. Journal of Cellular Biochemistry 200697 782-794. (https://doi.org/10.1002/jcb.20686)

59 Zauli G, Pandolfi A, Gonelli A, Di Pietro R, Guarnieri S, Ciabattoni G, Rana R, Vitale M \& Secchiero P. Tumor necrosis factor-related apoptosis-inducing ligand (TRAIL) sequentially upregulates nitric oxide and prostanoid production in primary human endothelial cells. Circulation Research 200392 732-740. (https://doi. org/10.1161/01.RES.0000067928.83455.9C)

60 Pritzker LB, Scatena M \& Giachelli CM. The role of osteoprotegerin and tumor necrosis factor-related apoptosis-inducing ligand in human microvascular endothelial cell survival. Molecular Biology of the Cell 200415 2834-2841. (https://doi.org/10.1091/mbc.e04-01-0059)

61 McGonigle JS, Giachelli CM \& Scatena M. Osteoprotegerin and RANKL differentially regulate angiogenesis and endothelial cell function. Angiogenesis 200912 35-46. (https://doi.org/10.1007/ s10456-008-9127-z)

62 Manuneedhi Cholan P, Cartland SP, Dang L, Rayner BS, Patel S, Thomas SR \& Kavurma MM. TRAIL protects against endothelial dysfunction in vivo and inhibits angiotensin-II-induced oxidative stress in vascular endothelial cells in vitro. Free Radical Biology and Medicine 2018126 341-349. (https://doi.org/10.1016/j. freeradbiomed.2018.08.031)

63 Chen PL \& Easton AS. Evidence that tumor necrosis factorrelated apoptosis inducing ligand (TRAIL) inhibits angiogenesis by inducing vascular endothelial cell apoptosis. Biochemical and Biophysical Research Communications 2010391 936-941. (https://doi. org/10.1016/j.bbrc.2009.11.168)

64 Chamley-Campbell J, Campbell GR \& Ross R. The smooth muscle cell in culture. Physiological Reviews 197959 1-61. (https://doi. org/10.1152/physrev.1979.59.1.1)

65 Secchiero P, Zerbinati C, Rimondi E, Corallini F, Milani D, Grill V, Forti G, Capitani S \& Zauli G. TRAIL promotes the survival, migration and proliferation of vascular smooth muscle cells. Cellular and Molecular Life Sciences 200461 1965-1974. (https://doi. org/10.1007/s00018-004-4197-6)

66 Harith HH, Di Bartolo BA, Cartland SP, Genner S \& Kavurma MM. Insulin promotes VSMC proliferation and apoptosis via differential regulation of TNF-related apoptosis inducing ligand. Journal of Diabetes 20158 568-578. (https://doi.org/10.1111/1753-0407.12339)

67 Azahri NSM, Di Bartolo BA, Khachigian LM \& Kavurma MM. Sp1, acetylated histone- 3 and p300 regulate TRAIL transcription: mechanisms of PDGF-BB-mediated VSMC proliferation and migration. Journal of Cellular Biochemistry 2012113 2597-2606. (https://doi.org/10.1002/jcb.24135)

68 Hameed AG, Arnold ND, Chamberlain J, Pickworth JA, Paiva C, Dawson S, Cross S, Long L, Zhao L, Morrell NW, et al. Inhibition of tumor necrosis factor-related apoptosis-inducing ligand (TRAIL) reverses experimental pulmonary hypertension. Journal of Experimental Medicine 2012209 1919-1935. (https://doi.org/10.1084/ jem.20112716)

69 Hayry P, Aavik E \& Myllarniemi M. Blockade of growth factor synthesis and growth factor action: two possible sites of interference in allograft vessel disease and coronary bypass or balloon injury. Metabolism: Clinical and Experimental 199645 (Supplement 1) 101-103. (https://doi.org/10.1016/s0026-0495(96)90097-9)

70 Leppanen O, Janjic N, Carlsson MA, Pietras K, Levin M, Vargeese C, Green LS, Bergqvist D, Ostman A \& Heldin CH. Intimal hyperplasia recurs after removal of PDGF-AB and -BB inhibition in the rat carotid artery injury model. Arteriosclerosis, Thrombosis, and Vascular Biology 200020 E89-E95. (https://doi.org/10.1161/01.atv.20.11.e89)

71 He C, Medley SC, Hu T, Hinsdale ME, Lupu F, Virmani R \& Olson LE. PDGFRbeta signalling regulates local inflammation and synergizes with hypercholesterolaemia to promote atherosclerosis. Nature Communications 20156 7770. (https://doi.org/10.1038/ncomms8770)

72 Dawson SH, Arnold N, Pickworth J, Francis S \& Lawrie A. TRAIL deficient mice are protected from Sugen/Hypoxia induced 
pulmonary arterial hypertension. Diseases 20142 260-273. (https:// doi.org/10.3390/diseases2030260)

73 Lawrie A, Waterman E, Southwood M, Evans D, Suntharalingam J, Francis S, Crossman D, Croucher P, Morrell N \& Newman C. Evidence of a role for osteoprotegerin in the pathogenesis of pulmonary arterial hypertension. American Journal of Pathology 2008 172 256-264. (https://doi.org/10.2353/ajpath.2008.070395)

74 Arnold ND, Pickworth JA, West LE, Dawson S, Carvalho JA, Casbolt H, Braithwaite AT, Iremonger J, Renshall L, Germaschewski V, et al. A therapeutic antibody targeting osteoprotegerin attenuates severe experimental pulmonary arterial hypertension. Nature Communications 201910 5183. (https://doi.org/10.1038/s41467-019-13139-9)

75 Di Bartolo BA, Chan J, Bennett MR, Cartland S, Bao S, Tuch BE \& Kavurma MM. TNF-related apoptosis-inducing ligand (TRAIL) protects against diabetes and atherosclerosis in Apoe(-)/(-) mice. Diabetologia 201154 3157-3167. (https://doi.org/10.1007/s00125-011-2308-0)

76 Secchiero P, Candido R, Corallini F, Zacchigna S, Toffoli B, Rimondi E, Fabris B, Giacca M \& Zauli G. Systemic tumor necrosis factor-related apoptosis-inducing ligand delivery shows antiatherosclerotic activity in apolipoprotein E-null diabetic mice. Circulation 2006114 1522-1530. (https://doi.org/10.1161/ CIRCULATIONAHA.106.643841)

77 Cartland SP, Genner SW, Martínez GJ, Robertson S, Kockx M, Lin RC, O'Sullivan JF, Koay YC, Manuneedhi Cholan P, Kebede MA, et al. TRAIL-expressing monocyte/macrophages are critical for reducing inflammation and atherosclerosis. iScience 201912 41-52. (https:// doi.org/10.1016/j.isci.2018.12.037)

78 Schoppet M, Sattler AM, Schaefer JR \& Hofbauer LC. Osteoprotegerin (OPG) and tumor necrosis factor-related apoptosis-inducing ligand (TRAIL) levels in atherosclerosis. Atherosclerosis $2006 \mathbf{1 8 4} 446-447$. (https://doi.org/10.1016/j.atherosclerosis.2005.10.028)

79 Volpato S, Ferrucci L, Secchiero P, Corallini F, Zuliani G, Fellin R, Guralnik JM, Bandinelli S \& Zauli G. Association of tumor necrosis factor-related apoptosis-inducing ligand with total and cardiovascular mortality in older adults. Atherosclerosis 2011215 452-458. (https://doi.org/10.1016/j.atherosclerosis.2010.11.004)

80 Pan X, Pang M, Ma A, Wang K, Zhang Z, Zhong Q \& Yang S. Association of TRAIL and its receptors with large-artery atherosclerotic stroke. PLOS ONE 201510 e0136414. (https://doi. org/10.1371/journal.pone.0136414)

81 Jono S, Ikari Y, Shioi A, Mori K, Miki T, Hara K \& Nishizawa Y. Serum osteoprotegerin levels are associated with the presence and severity of coronary artery disease. Circulation 2002106 1192-1194. (https:// doi.org/10.1161/01.cir.0000031524.49139.29)

82 Dhore CR, Cleutjens JP, Lutgens E, Cleutjens KB, Geusens PP, Kitslaar PJ, Tordoir JH, Spronk HM, Vermeer C \& Daemen MJ.
Differential expression of bone matrix regulatory proteins in human atherosclerotic plaques. Arteriosclerosis, Thrombosis, and Vascular Biology 200121 1998-2003. (https://doi.org/10.1161/ hq1201.100229)

83 Sato K, Niessner A, Kopecky SL, Frye RL, Goronzy JJ \& Weyand CM. TRAIL-expressing T cells induce apoptosis of vascular smooth muscle cells in the atherosclerotic plaque. Journal of Experimental Medicine 2006203 239-250. (https://doi.org/10.1084/jem.20051062)

84 Davenport C, Harper E, Rochfort KD, Forde H, Smith D \& Cummins PM. RANKL inhibits the production of osteoprotegerin from smooth muscle cells under basal conditions and following exposure to cyclic strain. Journal of Vascular Research $2018 \mathbf{5 5}$ 111-123. (https://doi.org/10.1159/000486787)

85 Bakhshian Nik A, Hutcheson JD \& Aikawa E. Extracellular vesicles as mediators of cardiovascular calcification. Frontiers in Cardiovascular Medicine 20174 78. (https://doi.org/10.3389/fcvm.2017.00078)

86 Durham AL, Speer MY, Scatena M, Giachelli CM \& Shanahan CM. Role of smooth muscle cells in vascular calcification: implications in atherosclerosis and arterial stiffness. Cardiovascular Research 2018114 590-600. (https://doi.org/10.1093/cvr/cvy010)

87 Di Bartolo BA, Cartland SP, Harith HH, Bobryshev YV, Schoppet M \& Kavurma MM. TRAIL-deficiency accelerates vascular calcification in atherosclerosis via modulation of RANKL. PLOS ONE 20138 e74211. (https://doi.org/10.1371/journal.pone.0074211)

88 Zauli G, Rimondi E, Stea S, Baruffaldi F, Stebel M, Zerbinati C, Corallini F \& Secchiero P. TRAIL inhibits osteoclastic differentiation by counteracting RANKL-dependent p27Kip1 accumulation in preosteoclast precursors. Journal of Cellular Physiology 2008214 117-125. (https://doi.org/10.1002/jcp.21165)

89 Chasseraud M, Liabeuf S, Mozar A, Mentaverri R, Brazier M, Massy ZA \& Kamel S. Tumor necrosis factor-related apoptosisinducing ligand and vascular calcification. Therapeutic Apheresis and Dialysis 201115 140-146. (https://doi.org/10.1111/j.17449987.2010.00886.x)

90 Galeone A, Brunetti G, Oranger A, Greco G, Di Benedetto A, Mori G, Colucci S, Zallone A, Paparella D \& Grano M. Aortic valvular interstitial cells apoptosis and calcification are mediated by TNF-related apoptosis-inducing ligand. International Journal of Cardiology 2013169 296-304. (https://doi.org/10.1016/j. ijcard.2013.09.012)

91 Rattazzi M, Bennett BJ, Bea F, Kirk EA, Ricks JL, Speer M, Schwartz SM, Giachelli CM \& Rosenfeld ME. Calcification of advanced atherosclerotic lesions in the innominate arteries of ApoE-deficient mice: potential role of chondrocyte-like cells. Arteriosclerosis, Thrombosis, and Vascular Biology 200525 1420-1425. (https://doi.org/10.1161/01.ATV.0000166600.58468.1b)

Received in final form 3 June 2020

Accepted 15 June 2020

Accepted Manuscript published online 16 June 2020 https://vb.bioscientifica.com

https://doi.org/10.1530/VB-20-0005 (c) 2020 The authors Published by Bioscientifica Ltd
This work is licensed under a Creative Commons Attribution-NonCommercial-NoDerivatives 4.0 International License. ded from Bioscientifica com at 04/25/2023 11:21:36PM 